\title{
ENSINO DE RECONHECIMENTO DE PALAVRAS NO CONTEXTO DA LEITURA DE HISTÓRIAS INFANTIS
}

\section{TEACHING WORD RECOGNITION IN THE CONTEXT OF READING CHILDREN'S $B O O K^{1}$}

\section{Lidia Maria Marson Postalli, Deborah Marçal Bueno de Almeida, Daniela de Souza Canovas e Deisy das Graças de Souza}

\author{
UNIVERSIDADE FEDERAL DE SÃO CARLOS, BRASIL
}

\begin{abstract}
RESUMO
A instalação e a manutenção do comportamento de ler dependem, como outros operantes, de conseqüências reforçadoras poderosas. A leitura de um principiante, porém, é insuficiente para gerar os reforçadores naturais do ler. Esse estudo verificou se o ensino de reconhecimento de palavras extraídas de histórias infantis, por meio de um procedimento de ensino sem erro que favorece a transferência de controle de estímulos do comportamento ecóico para o comportamento textual, afeta a aquisição e a manutenção de leitura. O procedimento de ensino era individualizado, implementado por computador. Foram ensinados oito conjuntos de 10 palavras (cada conjunto selecionado em um livro) e dois conjuntos foram empregados somente para avaliação, de acordo com um delineamento de linha de base múltipla entre conjuntos de palavras. Quando atingia o critério de aprendizagem de um conjunto, o participante tinha a oportunidade de ler o livro correspondente (com supervisão para feedback e ajuda, se necessário). O ensino de um novo conjunto só era iniciado depois que o aluno dominasse o anterior. Seis alunos com histórico de fracasso escolar aprenderam a reconhecer as palavras impressas na tela, mostraram retenção em testes subseqüentes e apresentaram níveis elevados de acertos no reconhecimento das mesmas palavras inseridas no texto, durante a leitura dos livros. Ao longo do estudo o desenvolvimento do controle textual foi se tornando cada vez mais rápido e menos dependente do ecóico. A aprendizagem alcançada sugere que o procedimento pode ser uma alternativa para o ensino de reconhecimento de palavras a leitores iniciantes, como um passo inicial a partir do qual pode ser ensinado o domínio do código arbitrário entre fonemas e grafemas que caracteriza a correspondência ponto a ponto que define o comportamento textual. A oportunidade de ler as histórias e identificar as palavras aprendidas no computador parece ter tido um significativo valor reforçador.
\end{abstract}

Palavras-chave: aprendizagem de leitura, reconhecimento de palavras, comportamento ecóico, comportamento textual, literatura infantil, motivação, crianças

\begin{abstract}
The acquisition and the maintenance of reading behavior, as any other operant, depend on powerful reinforcing consequences. The reading behavior of beginners, however, is usually insufficient to generate the natural reinforcers derived from reading. This study investigated whether teaching words of children's books through an errorless teaching procedure that promotes the transfer of stimulus control from echoic to textual behavior would affect the acquisition and maintenance of reading. A computerized procedure was designed to teach eight sets of 10 words each to individual participants. Each word set was composed of words from a single book. Two extra word sets were used for baseline assessment according to a multiple baseline design across word sets. After reaching accurate reading of a word set, the student had the opportunity to read the book from which the words had been selected. Reading the book was supervised by an adult, who modeled correct responding whenever necessary. A new word set was introduced only after the student showed proficiency in a previous set. Six students with a history of school failure learned to recognize printed words on the computer screen, showed reading retention in subsequent assessments, and presented high levels of accuracy in recognizing the same words when inserted in a connected text in the books. The development of textual control across successive word sets became increasingly faster and less dependent on echoic control. The results suggest that the procedure could be an appropriate alternative for teaching word recognition to beginning readers, as an initial step from which to proceed with teaching the arbitrary relations between phonemes and graphemes that characterize the point-to-point correspondence in textual behavior.

\footnotetext{
${ }^{1}$ A condução da pesquisa contou com apoio do PRONEX/FAPESP (\# 03/09928-4), com bolsas de iniciação cientifica do CNPq para as três primeiras autoras e bolsa de produtividade em pesquisa $(\mathrm{CNPq})$ para a quarta autora. Uma versão resumida foi publicada nos Anais (CD) do VII Encontro de Pesquisa em Educação da Região Sudeste, realizado em junho de 2005 na PUC Minas (Belo Horizonte, MG). As autoras agradecem o apoio generoso de Mônica L. Fonseca, Janaína R. Labadessa e Vera A. Periotto na coleta de dados, assim como o de alunos voluntários do curso de Graduação em Psicologia da UFSCar que colaboraram em diferentes fases do estudo. Agradecem, também, a dois revisores anônimos cujas sugestōes contribuíram para um substancial aprimoramento do texto. Correspondência para Lidia M.M. Postalli (lidiapostalli@yahoo.com.br) ou Deisy G.de Souza (ddgs@power.ufscar.br).
} 
The opportunity of reading the books and identifying the words previously learned in the computer seemed to have significant reinforcing value. children

Keywords: reading acquisition, word recognition, echoic behavior, textual behavior, children's books, motivation,

A baixa freqüência do comportamento de ler no ensino fundamental brasileiro e nos anos subseqüentes, é fonte de preocupação pelo prejuízo que decorre para a escolarização e para a formação geral do aluno (Duran, 1981; Witter, 1997).

Os baixos índices de leitura podem estar relacionados a fatores de diversas naturezas (nos âmbitos social, econômico, cultural). As dificuldades iniciais na aquisição desse repertório de natureza simbólica (que requer o domínio de um código, ou relaçôes arbitrárias som-texto) e a escassez de experiências individuais satisfatórias com a leitura, porém, podem estar na origem da falta de persistência e de engajamento nessa atividade (J. C. de Rose, 1999, 2005; T. M. S. de Rose, 1995; Snow, Griffin, \& Burns, 2005).

Como os demais comportamentos operantes, o comportamento de ler também precisa ser reforçado para ser estabelecido e mantido (Skinner, 1957). De acordo com de Rose (2005), após a criança ter adquirido algum comportamento textual, ouvir seu próprio comportamento poderá funcionar como reforço diferencial, permitindo que as respostas com sentido sejam fortalecidas e as sem sentido possam ser autocorrigidas.

O reforço diferencial decorrente da própria atividade de ler, aliado a outras conseqüências reforçadoras da leitura, como o acesso a informações ou conseqüências arbitrárias (por exemplo, elogios), pode aumentar a probabilidade da atividade de ler, ou seja, despertar o "gosto" ou "interesse" pela leitura (Santos \& de Rose, 1999, 2000). A literatura especializada e relatos de pais e professores indicam que as crianças geralmente gostam de ouvir histórias, contadas ou lidas para elas. Além disso, elas freqüentemente pedem que uma mesma história seja repetida muitas vezes. Tais relatos sugerem que ouvir histórias é naturalmente reforçador e poderia ser incorporado à situação de leitura; se a criança lê uma história que já ouviu ${ }^{2}$, ouvir a história lida por ela mesma pode prover os reforçadores que fortalecerão esse comportamento.

Para obter esse efeito natural (o prazer de ler) torna-se necessário proporcionar algumas condiçóes favoráveis à aquisição do comportamento textual e da leitura com compreensão. Um programa educacional deve incluir conseqüências reforçadoras arbitrárias para os comportamentos acadêmicos, até que os mesmos estejam suficientemente fortalecidos para produzirem suas conseqüências naturais; porém, o uso exclusivo de reforços arbitrários nos sistemas educacionais resulta na formação de um contingente de leitores que não chega a desenvolver uma boa compreensão do que lê, nem desenvolve o gosto pela leitura. Portanto, faz-se necessária a redução gradual de reforços arbitrários (aqueles apresentados pelo professor, por exemplo), à medida que o aluno torna-se sensível aos reforçadores naturais, ou seja, aqueles inerentes à própria atividade (de Rose, 2005; Ferster, 1967; Santos \& de Rose,

${ }^{2}$ Uma estratégia amplamente empregada no bem sucedido programa Reading Recovery desenvolvido por Clay (1993). 
1999, 2000). Os reforçadores naturais dos desempenhos acadêmicos, entre os quais os efeitos da aprendizagem que deles resulta podem, por si só, garantir a manutenção dos desempenhos acadêmicos, de modo que os estudantes tenham suficiente "incentivo" para permanecer "interessados" e engajados nas atividades acadêmicas (de Rose, 1999, 2005).

Interesse e motivação expressam-se pela tendência do indivíduo em engajar-se em algum comportamento. Assim, identifica-se o interesse de uma pessoa por leitura quando ela lê com freqüência e, também, engaja-se em comportamentos precorrentes, isto é, comportamentos que possibilitam a ocorrência de ler, como procurar livros, folhear livros, comprar livros, freqüentar bibliotecas, etc. (Santos \& de Rose, 1999).

Santos e de Rose (2000) enfatizaram a importância da leitura de bons livros que, segundo Skinner (1957), podem funcionar como reforçadores intermitentes, referindo-se àquelas obras em que o suspense e o enigmático prevalecem por algum tempo. Assim, entre as conseqüências naturais da leitura, encontra-se o tipo de conteúdo do livro. A permanência na atividade de ler seria mantida pelo suspense do enredo e pela curiosidade do leitor em ter acesso ao desenrolar da história (Santos \& de Rose, 1999). Nesse sentido, é compreensível que o uso de livros predominantemente didáticos nas escolas seja pouco motivador para os alunos (da Silva, Sparano, Cerri, \& Carbonari, 1997; Santos \& de Rose, 1999).

$\mathrm{O}$ interesse em ler e o efetivo engajamento do aluno na leitura de outros textos que não apenas os exigidos pelo professor são muitas vezes considerados como intrínsecos ao aluno, dependendo exclusivamente de motivação (que se supõe ser uma característica do aluno) e de sua "vontade" de ler (Santos \& de Rose, 1999).
No entanto, a pesquisa psicológica evidencia que a freqüência do comportamento está relacionada aos efeitos ou resultados que ele produz no ambiente; no caso da leitura, está relacionado às conseqüências reforçadoras contingentes ao comportamento de ler (de Rose, 2005; Skinner, 1957).

Conseqüências reforçadoras naturais para ler, no entanto, não estão facilmente acessíveis ao aluno que ainda não aprendeu essa habilidade. É preciso, para isto, preencher a lacuna de repertório entre o não ler e o ler. Uma alternativa para isto é introduzir reforçadores arbitrários na fase de ensino e retirá-los gradualmente, à medida que o comportamento vai se desenvolvendo (Ferster, 1967). Como estratégia para chegar ao reforçamento natural para o comportamento de ler, ou seja, fazer com que as conseqüências naturalmente reforçadoras aumentem a tendência do indivíduo em engajarse futuramente no comportamento, os reforçadores arbitrários empregados na fase inicial do processo devem ser funcionais para modelar, aumentar e manter o comportamento e, com isso, proporcionar condição para a ocorrência de conseqüências reforçadoras naturais (Horcones, 1992).

Considerando os argumentos de que conseqüências reforçadoras quando contingentes ao comportamento aumentam a tendência de ocorrência do mesmo e que o tipo do conteúdo do livro pode incluir consequiências naturais para a leitura, o presente estudo foi desenvolvido buscando-se implementar um procedimento de ensino que ao mesmo tempo minimizasse os erros durante a aprendizagem e ensinasse palavras inseridas em contexto, selecionadas em livros de histórias infantis. Se o aluno aprendesse o comportamento textual (falar palavras sob controle de palavras impressas) e compreendesse 
seu significado ao encontrar as mesmas palavras no livro de histórias, este poderia ser o início de uma transição de uma situação de reforço arbitrário para uma de reforço natural (de Rose, 1999, 2005; Ferster, 1967; Santos \& de Rose, 1999, 2000). O objetivo do estudo, portanto, foi verificar os efeitos, sobre o reconhecimento de palavras impressas, de se aliar o ensino de comportamento textual a um conteúdo com potencial valor reforçador. As palavras ensinadas eram selecionadas de livros de histórias infantis cuja versão oral os alunos conheciam, por terem participado de sessões prévias, em uma situação lúdica, nas quais um adulto lia as histórias para grupos de alunos. Logo depois de aprender um conjunto de palavras de uma história, pelo procedimento conduzido por meio do computador, o aluno tinha a oportunidade de, pela primeira vez, ler a história no livro. Um objetivo adicional foi o de replicar os efeitos do procedimento, que se apóia inicialmente no comportamento ecóico (já presente no repertório dos alunos) e promover a transferência gradual de controle do modelo verbal para o texto (Gallo \& de Souza, 2004; Harzem, Lee \& Miles, 1976). No estudo de Gallo e de Souza (2004) alunos com histórico de fracasso escolar e pouco interesse manifesto em leitura foram expostos ao procedimento, implementado por computador, que apresentava, a cada tentativa, uma palavra impressa na tela do monitor e, simultaneamente, a mesma palavra ditada. A tarefa do aluno consistia apenas em dizer a palavra. Começando por uma tarefa fácil (repetir o que ouve), o procedimento possibilitava a transferência de controle discriminativo de estímulos verbais orais para estímulos verbais impressos. A aprendizagem podia ser monitorada gradualmente, alternando-se tentativas de ensino (com apresentação simultânea da palavra impressa e da palavra ditada) de um conjunto de palavras com tentativas de sonda (nas quais apenas a palavra impressa era apresentada) das mesmas palavras.

No presente estudo foram ensinados oito conjuntos de 10 palavras e, além da monitoração da aquisição do comportamento textual durante o ensino de cada conjunto, foi também empregado um delineamento de linha de base múltipla entre conjuntos de palavras, visando aferir a validade interna do procedimento. Adicionalmente, foi medida a extensão do controle de estímulos de palavras isoladas para palavras apresentadas como elementos de um texto curto de livro de história.

\section{Método}

\section{Participantes}

Participaram seis alunos de uma escola pública de ensino fundamental de uma cidade do interior de São Paulo, cinco meninos e uma menina, membros de famílias de nível sócioeconômico baixo. A Tabela 1 mostra que os alunos, em geral, apresentavam idade acima da esperada para a série (exceto a menina) e obtiveram escores muito baixos em uma tarefa de avaliação de leitura de palavras isoladas realizada para a seleção de participantes. Para participar do estudo o aluno deveria estar freqüentando a escola.

\section{Situação}

O estudo, aprovado pelo Comitê de Ética da Universidade Federal de São Carlos, foi realizado na Unidade de Iniciação à Leitura, instalada na Biblioteca Comunitária da Universidade. As sessões de ensino eram conduzidas cinco dias por semana. Os alunos eram transportados da escola até a Universidade por um 
Tabela 1

Código de identificação do participante, sexo, idade cronológica, série escolar e desempenho em avaliação inicial de leitura.

\begin{tabular}{ccccc}
\hline $\begin{array}{c}\text { Código de } \\
\text { Identificação }\end{array}$ & Sexo(M/F) & $\begin{array}{c}\text { Idade } \\
\text { (anos: meses) }\end{array}$ & Série Escolar & $\begin{array}{c}\text { Leitura Inicial } \\
(\%)\end{array}$ \\
\hline CHL & M & $9: 1$ & $2^{\mathrm{a}}$ & 0 \\
RAS & $\mathrm{M}$ & $8: 9$ & $3^{\mathrm{a}}$ & 0 \\
CRL & $\mathrm{M}$ & $13: 10$ & $6^{\mathrm{a}}$ & 13,3 \\
FAJ & $\mathrm{M}$ & $8: 4$ & $2^{\mathrm{a}}$ & 33,3 \\
TEO & $\mathrm{F}$ & $7: 6$ & $1^{\mathrm{a}}$ & 20 \\
MVS & $\mathrm{M}$ & $9: 1$ & $3^{\mathrm{a}}$ & 20 \\
\hline
\end{tabular}

transporte escolar, em horário alternado ao de seu período de aulas, mediante autorização dos pais e da direção da escola.

$\mathrm{O}$ estudo fez uso de três ambientes da biblioteca: o Setor de Literatura Infantil, uma sala pequena para trabalho em pequenos grupos e a Unidade de Iniciação à Leitura.

No Setor de Literatura Infantil, equipado com mesas, cadeiras e com almofadas, ao lado do acervo, os participantes tinham a oportunidade de manusear livros de histórias e de ouvir histórias lidas por um monitor (adulto, leitor) que supervisionava as atividades nesse ambiente. Na Unidade de Iniciação à Leitura, equipada com estações de trabalho com computadores para trabalho individualizado, cada participante realizava as tarefas informatizadas previstas pelo procedimento para ensino de palavras. $\mathrm{Na}$ sala para pequenos grupos, o aluno trabalhava individualmente com um experimentador /monitor, na leitura dos livros de histórias.

\section{Materiale Equipamento}

O programa de ensino foi aplicado por meio de um microcomputador PC equipado com tela sensível ao toque (Microtouch) de 17 polegadas, instalado sobre uma estação de trabalho construída de modo a permitir que cada aluno trabalhasse individualmente de frente para a tela, com ligeiro bloqueio lateral de outras estimulações do ambiente ao redor. Para o gerenciamento do procedimento de ensino e do registro de dados foi empregado o software Aprendendo a ler e a escrever em pequenos passos (Rosa Filho, de Rose, de Souza, Hanna, \& Fonseca, 1998). As instruções orais e os demais estímulos auditivos eram apresentados por meio de fones de ouvido, de modo a possibilitar a aplicação simultânea com vários alunos e garantir a qualidade da estimulação auditiva apresentada. Os estímulos visuais, apresentados na tela do microcomputador, eram palavras impressas em fonte Arial, tamanho 65.

Foram utilizados também livros de histórias infantis que fazem parte da Coleção Gato e Rato, editada pela Editora Ática, de autoria de Mary França e Eliardo França. Os livros são ilustrados, apresentam apenas uma sentença por página e as palavras-chave são repetidas ao longo da história, o que torna o material acessível ao leitor iniciante. A seqüência dos livros foi organizada em dois módulos, com cinco livros 
em cada módulo, de acordo com as dificuldades apresentadas nas histórias. De cada livro foi selecionado um conjunto de 10 palavras, que eram ensinadas em uma mesma "lição" ou passo. $\mathrm{Na}$ Tabela 2 estão listados os livros selecionados para cada módulo, a ordem em que foram trabalhados e as 10 palavras selecionadas em cada livro, para ensino ou avaliação. No primeiro módulo, os livros selecionados continham palavras simples (do tipo consoante-vogal) e apresentavam histórias estruturadas. Os livros selecionados para o Módulo 2 continham, também, palavras com dificuldades da língua (encontros consonantais, dígrafos, etc). As palavras selecionadas incluíam principalmente substantivos e verbos, mas ocasionalmente foram selecionados adjetivos e pronomes. $\mathrm{O}$ critério de seleção era o de palavras mais freqüentes na história (visando garantir uma maior probabilidade de que o aluno encontrasse as palavras ensinadas quando fosse exposto à história pela primeira vez).

\section{Tabela 2}

Livros empregados: seqüência no programa, título e palavras selecionadas para avaliação e ensino, em cada um dos dois módulos.

\begin{tabular}{|c|c|c|}
\hline Seqüência & Título do Livro & Palavras selecionadas ${ }^{\text {a }}$ \\
\hline \multicolumn{3}{|r|}{ Módulo 1} \\
\hline 1 & "O rabo do gato" & sapo, rabo, gato, tatu, novo, viu, ficou, veio, falou, sou \\
\hline 2 & "O pote de melado" & $\begin{array}{l}\text { rato, pato, melado, vovó, pote, vem, vamos, comer, pulou, } \\
\text { pegou }\end{array}$ \\
\hline 3 & "A bota do bode" & $\begin{array}{l}\text { bota, bode, patas, galo, casa, filhotes, colocou, deu, sumiu, } \\
\text { andou }\end{array}$ \\
\hline 4 & "Fogo no céu" & $\begin{array}{l}\text { fogo, céu, coruja, balão, mata, fugiu, cair, apagar, pendurou, } \\
\text { deram }\end{array}$ \\
\hline $5^{b}$ & “O pega-pega" & pega, você, nada, longe, pegar, vai, vou, sabe, ria, é \\
\hline \multicolumn{3}{|r|}{ Módulo 2} \\
\hline 6 & "A boca do sapo" & $\begin{array}{l}\text { boca, beira, rio, grande, pequena, coelho, bolo, velas, } \\
\text { respondeu, disse }\end{array}$ \\
\hline 7 & "O barco" & $\begin{array}{l}\text { barco, tartaruga, montanhas, onça, papai, mamãe, jacaré, } \\
\text { índio, navegar, passa }\end{array}$ \\
\hline 8 & "O vento" & $\begin{array}{l}\text { vento, janelas, flores, varal, chapéu, rosto, roupa, soprou, } \\
\text { levou, jogou }\end{array}$ \\
\hline 9 & "Chuva" & $\begin{array}{l}\text { chuva, telhado, mar, galho, campo, gaivota, navio, peixe, } \\
\text { molha, vê }\end{array}$ \\
\hline $10^{\mathrm{b}}$ & “Surpresas!” & $\begin{array}{l}\text { barulho, bichos, tamanduá, papagaio, surpresa, porco- } \\
\text { espinho, serelepe, cachorro, tinha, foram }\end{array}$ \\
\hline
\end{tabular}

a Os substantivos e verbos foram ensinados no número ou gênero, e pessoa ou tempo em que ocorriam na história da qual foram selecionados.

b As palavras dos Livros 5 e 10 entraram na lista de palavras avaliadas no início e no final de cada "lição" para medida de linha de base e de generalização, mas não foram diretamente ensinadas. 


\section{Procedimento geral}

O estudo consistiu em ensinar conjuntos de 10 palavras, cada conjunto selecionado de um livro de história e, após o ensino de cada conjunto, dar ao aluno a oportunidade de ler a história inteira. Foram ensinados oito conjuntos de 10 palavras, divididos em dois módulos de quatro conjuntos cada; dois outros conjuntos foram reservados para avaliação de generalização, um ao final do Módulo 1 e outro ao final do Módulo 2 (ver Tabela 2). O procedimento de ensino foi implementado como parte de uma sequiência de tarefas, algumas das quais tinham o propósito de familiarizar o aluno com cada história e, também, de avaliar os efeitos do procedimento. A seqüência geral de tarefas foi a seguinte: pré-teste de leitura, aplicação do procedimento de ensino nos dois módulos (portanto uma seqüência de oito conjuntos de palavras ou "liçôes") e pós-teste de leitura.

No procedimento de ensino cada lição, por sua vez, envolvia a seguinte seqüência geral: familiarização do aluno com a história lida por um adulto (portanto, conhecimento prévio da história oral); pré-teste das palavras a serem ensinadas e das palavras dos outros quatro livros do mesmo módulo (medida de linha de base das palavras ainda não ensinadas e de retenção das palavras já ensinadas); exposição ao procedimento informatizado até que o critério (dizer as 10 palavras diante apenas da palavra impressa na tela) fosse atingido; leitura da história pelo aluno (com supervisão de um monitor).

Ao final de cada módulo o aluno era exposto à leitura de um quinto livro cujas palavras haviam sido avaliadas nos testes sucessivos, mas não ensinadas.

Avaliação de leitura inicial e final (pré-e pósteste). Uma avaliação do repertório de leitura foi realizada antes e depois da aplicação do programa de ensino. Para esta finalidade foi empregado um conjunto de 15 palavras simples (bolo, boneca, caju, camelo, dedo, faca, gaveta, lima, loja, menina, mula, sacola, salada, tapete, tubo) que eram apresentadas uma a uma, na parte superior da tela do monitor e o aluno era instruído a dizer qual era a palavra. Essas palavras foram empregadas apenas nos testes.

Familiarização com as histórias apresentadas oralmente. No Setor de Literatura Infantil da biblioteca, um dos experimentadores lia histórias infantis para grupos de alunos, que acompanhavam a história apenas ouvindo e tinham a oportunidade de ver as ilustraçôes, mas não de ler o texto. Após terminar a leitura de um livro, o experimentador fazia perguntas visando ampliar a compreensão da história, como, por exemplo, "Quem gostou da história?", "Sobre o que é esta história?”, "Quais eram os personagens?", "O que aconteceu com o....?”, "O que fez a...?", "Onde estavam as ...., quando...", "Como termina a história?" Antes do ensino individualizado de cada conjunto de palavras, a história correspondente era novamente lida para o aluno, desta vez individualmente.

Procedimento de ensino. O procedimento de ensino propriamente dito era gerenciado pelo microcomputador. Para o ensino de cada conjunto de palavras, o procedimento era constituído por dois blocos de 10 tentativas cada, um de ensino e o outro de sondas, com as mesmas 10 palavras.

Em cada tentativa de ensino uma palavra impressa era apresentada no centro da tela do monitor, simultaneamente à apresentação, por meio do fone de ouvido, da palavra ditada. A tarefa do aluno era dizer a palavra, o que poderia ser feito sob controle apenas da palavra ditada (comportamento ecóico), apenas da palavra impressa (comportamento textual), ou de 
ambos os estímulos. O objetivo era estabelecer o comportamento textual; começar com o ecóico, simultaneamente, era a estratégia para garantir alta densidade de reforçamento nessa fase inicial, uma vez que repetir o que outro diz, mesmo sem pistas orofaciais, fazia parte do repertório dos alunos. No início de cada sessão de ensino, era apresentada a seguinte instrução: "O computador vai mostrar uma palavra e dizer o que está escrito. Toda vez que aparecer uma palavra, você deve dizer qual é a palavra”.

Uma tentativa era encerrada quando o participante dissesse a palavra ou 20 segundos depois do início da apresentação da palavra impressa na tela. Durante a presença da palavra na tela, enquanto não ocorresse uma resposta, o estímulo auditivo era re-apresentado a cada 2 segundos. Se nenhuma resposta ocorresse, depois de 20 segundos a tentativa era encerrada e a tentativa seguinte era apresentada. Respostas corretas eram consequenciadas com sons digitalizados e/ou com elogios previamente gravados e apresentados pelo alto-falante do computador. Respostas incorretas eram apenas seguidas pela tentativa seguinte, até que se completasse a sequiência com as 10 palavras.

Tentativas de sonda eram implementadas na seqüência das tentativas de ensino, sem interrupções. A cada tentativa apenas a palavra impressa era apresentada, o que permitia avaliar isoladamente o comportamento textual. Era conduzida uma seqüência de 10 tentativas; as palavras eram as mesmas do bloco de ensino, mas eram apresentadas em uma seqüência diferente.

Os dois blocos (um de ensino e um de sonda) eram conduzidos em seqüência, constituindo um ciclo. A Figura 1 apresenta o fluxograma desse procedimento dentro de uma sessão de ensino. Em cada sessão eram realizados três ciclos e eram realizadas quantas sessões fossem necessárias para que o aluno apresentasse $100 \%$ de acertos nos blocos de sondas dos três ciclos. A cada apresentação de um bloco, a seqüência de palavras era diferente das anteriores, tanto para os blocos de ensino, quanto para os blocos de sondas. Quando o aluno atingia o critério, o treino era encerrado e ele tinha a oportunidade de ler a história no livro que continha as palavras recém-aprendidas.

Leitura de história. Na sessão de leitura, introduzida pela experimentadora como um prêmio pelo fato de ter completado o treino, o participante era encorajado a ler, em voz alta, o livro de história infantil. A leitura era acompanhada pela experimentadora, que tinha a dupla função de aplicar o procedimento e fazer o registro de dados.

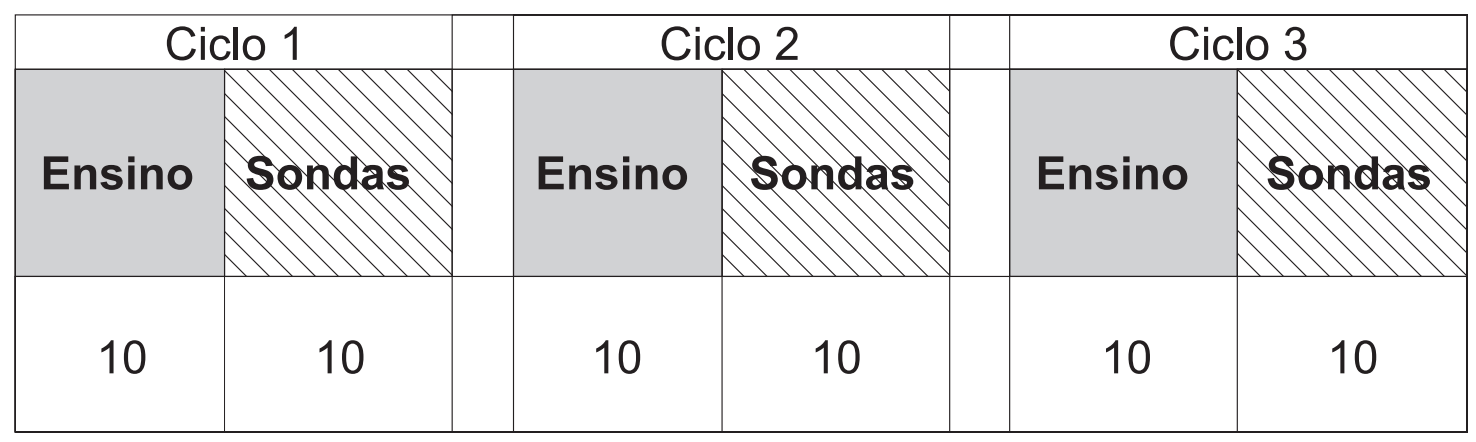

Figura 1. Fluxograma do procedimento informatizado dentro de uma sessão de ensino. Cada ciclo, com um bloco de 10 tentativas de ensino seguido por um bloco de 10 tentativas de sondas com as mesmas 10 palavras, era repetido três vezes em uma sessão de 60 tentativas, independente da porcentagem de acertos. O critério para passar para um novo conjunto de palavras era $100 \%$ de acertos nos três blocos de sondas. 
O procedimento, previamente desenvolvido e testado por Miura (1992), envolvia o uso de modelo da resposta correta. A experimentadora acompanhava atentamente o desempenho do aluno e, se necessário, fornecia ajuda, que consistia simplesmente em dizer a palavra correta (isto é, apresentar um modelo de resposta), sem qualquer outro comentário. $\mathrm{O}$ modelo podia ser apresentado como uma correção ou como uma dica. A correção era apresentada imediatamente após uma emissão incorreta por parte do aluno. Uma dica atrasada era apresentada sempre que transcorresse um certo período de tempo sem resposta, no fluxo da leitura. Portanto, o procedimento tinha início com a oportunidade, para o aluno, de ler por si mesmo; enquanto ele prosseguisse com a leitura correta, o adulto permanecia como uma audiência silenciosa, mas interessada; se ele lesse incorretamente ou depois de alguns segundos sem resposta (o que sugeria que estava encontrando dificuldade), a experimentadora apresentava o modelo. $\mathrm{O}$ aluno era instruído a repetir o modelo e prosseguir. Se o aluno lesse uma palavra incorretamente, mas imediatamente depois fizesse a leitura correta, a resposta era classificada como uma auto-correção e a experimentadora elogiava a resposta correta. A análise dos dados de leitura era feita para cada palavra, independente de sua extensão ou função no texto. A resposta oral diante de cada palavra impressa era classificada como: correta, modelo-correção, modelo-dica, autocorreção, ou incorreta.

Ao longo da sessão de leitura a experimentadora consequenciava socialmente o comportamento do aluno, fazendo comentários elogiosos sobre seu desempenho ou outros comentários sobre algum aspecto da história. A sessão de leitura era finalizada quando o par- ticipante concluía a leitura do livro. Depois da leitura de um livro, o aluno voltava, nas sessões subseqüentes, a participar das atividades de ensino individualizado no computador com um novo conjunto de palavras referentes ao livro seguinte e assim por diante, até completar a leitura do quarto livro do Módulo 1. Depois de ler o quarto livro, sem qualquer treino adicional, o aluno tinha a oportunidade de ler um quinto livro cujas palavras não tinham sido objeto de ensino (mas do qual um conjunto de 10 palavras havia sido selecionado para avaliar a leitura do aluno antes do ensino de cada um dos quatro conjuntos precedentes). O Módulo 2 era uma replicação do Módulo 1, com novos livros. A Tabela 2 apresenta a lista de livros e as palavras selecionadas em cada um deles.

Delineamento Experimental. Além das medidas de pré- e pós-teste com um conjunto de palavras que não seriam empregadas na fase de ensino, foi empregado também um delineamento de linha de base múltipla (Sidman, 1960/ 1976; Tawney \& Gast, 1984) entre os conjuntos de palavras, para cada um dos dois módulos. A linha de base de cada módulo era constituída por 50 palavras (as 10 selecionadas de cada livro). A avaliação dessa linha de base foi dividida em dois blocos de 25 palavras; cada bloco era conduzido em uma sessão. Cada palavra impressa era apresentada no centro da tela e o aluno era instruído a dizer qual era a palavra. A avaliação era aplicada antes do ensino de cada novo conjunto de palavras; portanto, foram conduzidas cinco avaliaçôes em cada módulo. A sequiência de tentativas era reorganizada a cada nova avaliação. Após a medida de linha de base inicial de leitura de todas as 50 palavras, era ensinado o primeiro conjunto de 10 palavras, enquanto as outras 40 continuavam em linha de base. Atingindo o critério para o primeiro conjunto, 
nova avaliação era conduzida. Quando o segundo conjunto era ensinado, haviam sido tomadas duas medidas da linha de base das palavras desse conjunto, antes de serem ensinadas. Seguindo essa seqüência, obteve-se, respectivamente, uma, duas, três e quatro medidas antes do ensino de cada um dos quatro conjuntos em cada módulo, respectivamente. Como as palavras ensinadas continuavam sendo incluídas nas avaliaçôes de linha de base subseqüentes, as avaliações após o treino permitiam monitorar a retenção de leitura das palavras já ensinadas. O conjunto 5 de cada módulo foi mantido em linha de base, com cinco medidas sucessivas, o que permitiu verificar se a aprendizagem das palavras dos outros quatro livros promovia ou não leitura generalizada dessas palavras.

As medidas de linha de base, além de indicarem se o ensino era eficaz, também permitiam identificar se ocorria leitura generalizada. Aumentos sistemáticos na leitura de palavras ainda não ensinadas, mantidas em linha de base, indicariam efeitos de generalização da aprendizagem de leitura nos passos já ensinados para palavras ainda não ensinadas. A leitura generalizada, isto é, leitura de novas palavras formadas por recombinaçôes de letras e sílabas de palavras já ensinadas poderia ocorrer antes do ensino direto. Por exemplo, ensinadas as palavras rabo e gato (Livro 1), a leitura correta de rato (Livro 2) ou de bota (Livro 3) poderia ser considerada um caso de leitura recombinativa (Alessi, 1987; Goldstein, 1983), uma vez que o ensino incidiu somente sobre palavras inteiras e a leitura de sílabas recombinadas pode ser interpretada como indício de desenvolvimento de controle textual por unidades menores que as palavras. As medidas das 10 palavras nos passos 5 e 10 eram especialmente apropriadas para esta avaliação, uma vez que nunca foram ensinadas (apenas avaliadas, misturadas às outras 40 , nas avaliações sucessivas de linha de base).

$\mathrm{Na}$ leitura das histórias era verificado se ocorria a extensão do controle de estímulos de palavras isoladas para palavras apresentadas como parte de um texto (isto é, o aluno reconheceria, em outro suporte ou ambiente, em meio a várias outras palavras, aquelas que havia aprendido a reconhecer na tela do computador, quando era apresentada isolada, no centro da tela e em fonte em tamanho maior?). Em outras palavras, haveria convergência no reconhecimento das palavras no computador e no texto? Nessa situação também era possível verificar se o aluno era capaz de ler outras palavras que não aquelas diretamente ensinadas, especialmente na leitura dos livros 5 e 10, cujas palavras foram apenas avaliadas.

\section{Resultados e Discussão}

O estudo teve como objetivo ensinar reconhecimento de palavras por meio de um procedimento de aprendizagem sem erro, empregando palavras selecionadas de histórias infantis e criar oportunidades para que o aluno lesse a história e experimentasse sucesso ao fazer isso, uma vez que poderia reconhecer, no livro, palavras aprendidas na situação de ensino. As perguntas eram se os resultados de aquisição de controle pelo texto replicariam os de um estudo prévio, no qual o mesmo procedimento foi empregado para ensinar outros conjuntos de palavras, e se as contingências programadas manteriam o comportamento de ler na situação de leitura de histórias.

Para efeito de análise de dados, os seis participantes foram distribuídos com base nos resultados obtidos na avaliação inicial (Tabela 
1): os três primeiros, em cada gráfico ou tabela, apresentaram baixa porcentagem de acertos como repertório de entrada (nenhuma palavra lida); os outros três leram entre três e cinco das 15 palavras avaliadas.

Efeitos sobre o reconhecimento de palavras (comportamento textual)

Os escores dos seis participantes na tarefa de reconhecimento de palavras impressas no pré- e no pós-teste são apresentados na Figura 2. O desempenho inicial em leitura era baixo para todos os participantes ( $0 \%$ para os participantes na coluna esquerda e de $20 \%$ a $33 \%$ para os participantes na coluna da direita), mas aumentou substancialmente para todos eles, após a exposição ao procedimento de ensino: dois participantes leram $86,7 \%$ e os outros quatro leram 100\% das 15 palavras. Embora as palavras empregadas nessa avaliação fossem relativamente fáceis (apenas dissílabas e trissílabas constituídas por sílabas simples, do tipo consoante-vogal), a diferença do pré- para o pós-teste mostra que os alunos passaram a apresentar o comportamento textual. Além dis-

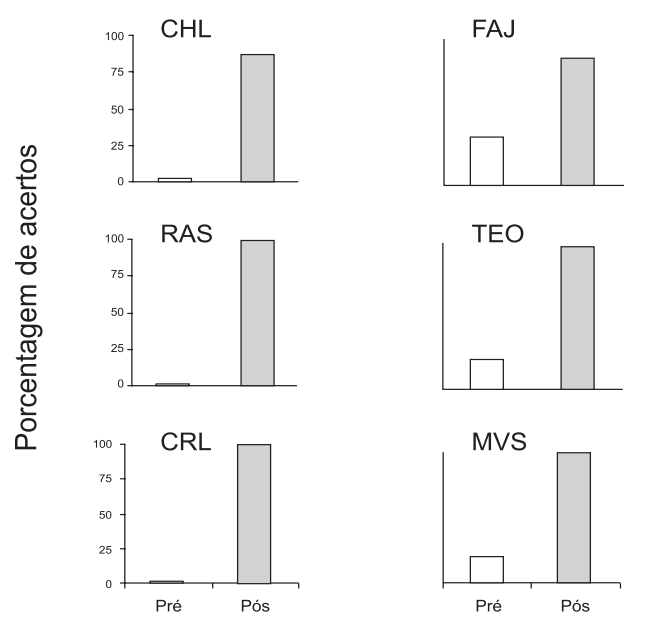

Avaliações de comportamento textual inicial e final

Figura 2. Porcentagem de acertos para participantes individuais na avaliação de comportamento textual, no pré-teste (barras brancas) e no pós-teste (barras cinzas). so, as palavras foram empregadas apenas nos testes, o que sugere tratar-se de um desempenho generalizado; não generalização por similaridade física, mas por recombinação de unidades (cf. Alessi, 1987; Goldstein, 1983). Contudo, não se pode descartar a possibilidade de que os alunos tenham aprendido a ler na escola. Por isso foi importante o delineamento de linha de base múltipla entre palavras, a ser discutido no contexto de apresentação dos dados da fase de ensino.

$\mathrm{O}$ aumento de repertório na avaliação final confirma os dados obtidos por Gallo e de Souza (2004) com o mesmo procedimento e estendem tais resultados para novos conjuntos de palavras que também incluíram verbos (o estudo anterior ensinou apenas substantivos) .

As Figuras 3 e 4 apresentam o desempenho dos alunos durante a aplicação do procedimento de ensino por meio do microcomputador, nos Módulos 1 e 2, respectivamente. Cada linha apresenta os dados de um participante. No eixo das ordenadas está apresentada a porcentagem de acertos em cada bloco de tentativas e no eixo das abscissas encontram-se os sucessivos ciclos (ver fluxo na Figura 1). Um ciclo incluía um bloco de ensino e um bloco de sondas; por essa razão, no eixo correspondente a um ciclo a figura apresenta dois dados: os acertos no bloco de ensino (triângulos vazios) e os acertos no bloco de sondas (círculos cheios).

Nos blocos de ensino todos os participantes apresentaram $100 \%$ de acertos, em praticamente todas as sessóes. Esse resultado era esperado, devido às características do procedimento empregado, que envolvia o comportamento ecóico, amplamente instalado no repertório dos alunos. Esperava-se que esse componente favorecesse a transferência de controle de estímulos 
Conjuntos de palavras ensinadas

1
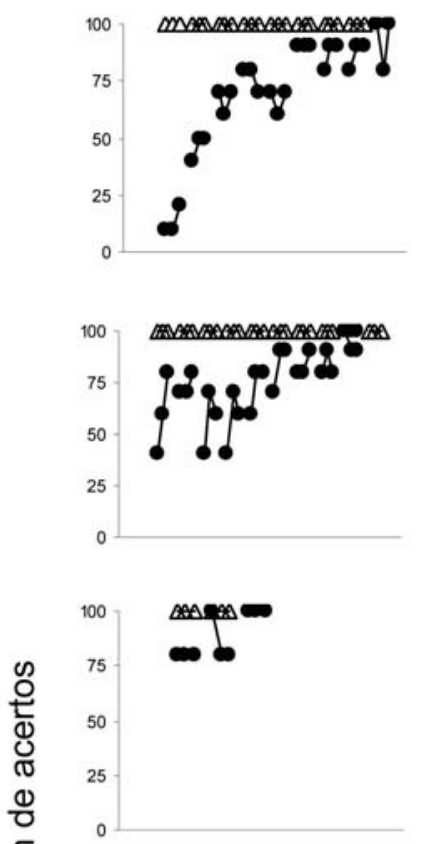

8
0
0
$\pi$
$\frac{\pi}{2}$
0
0
0
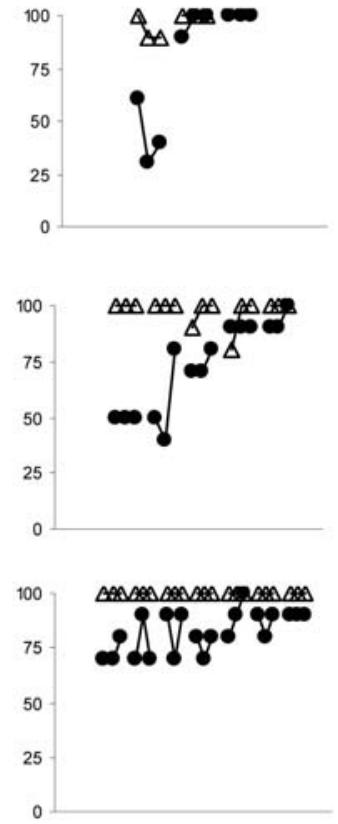

2
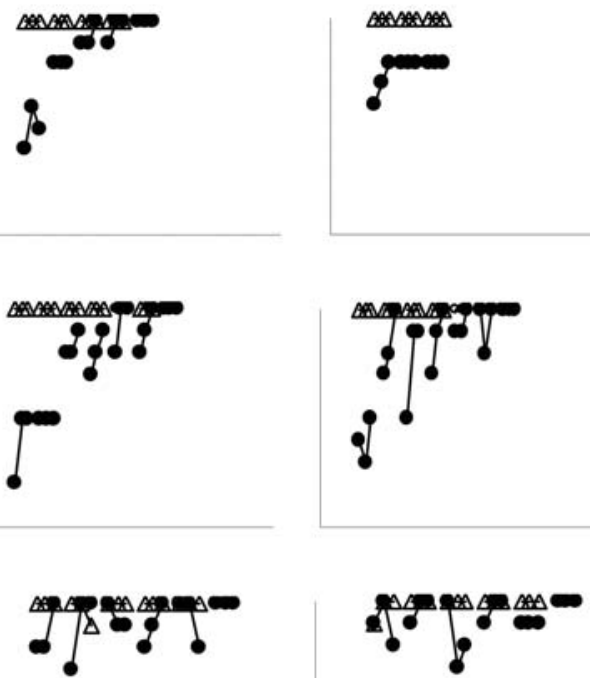

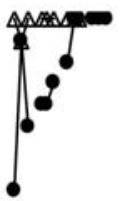

$\mathrm{CHL}$

RAS
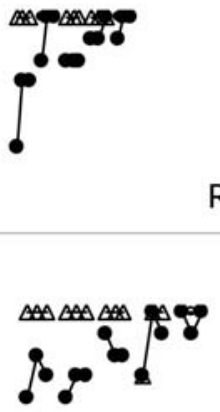

CRL
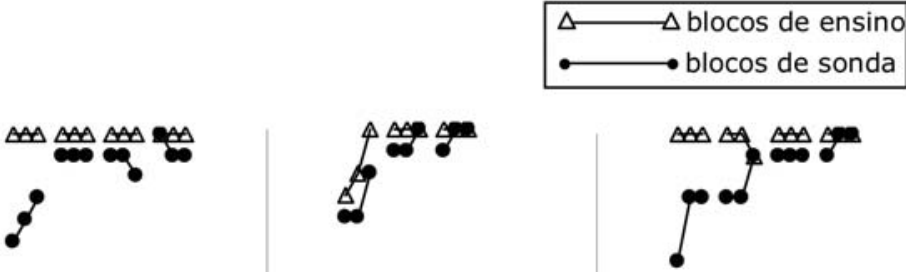

FAJ
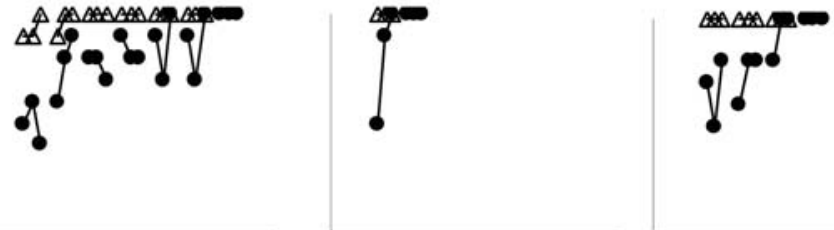

MVS

\section{Ciclos de ensino e sondas}

Figura 3. Porcentagem de acertos na leitura de palavras, em blocos sucessivos de tentativas de ensino (triângulos vazios) e de sondas (círculos cheios), para cada participante ao longo dos quatro conjuntos de palavras no Módulo 1. Cada ponto representa um bloco de 10 tentativas e cada conjunto de três blocos representa uma sessão. Os blocos de ensino e de sondas para um mesmo valor no eixo das abscissas pertencem a um mesmo ciclo. 


\section{Conjuntos de palavras ensinadas}

1
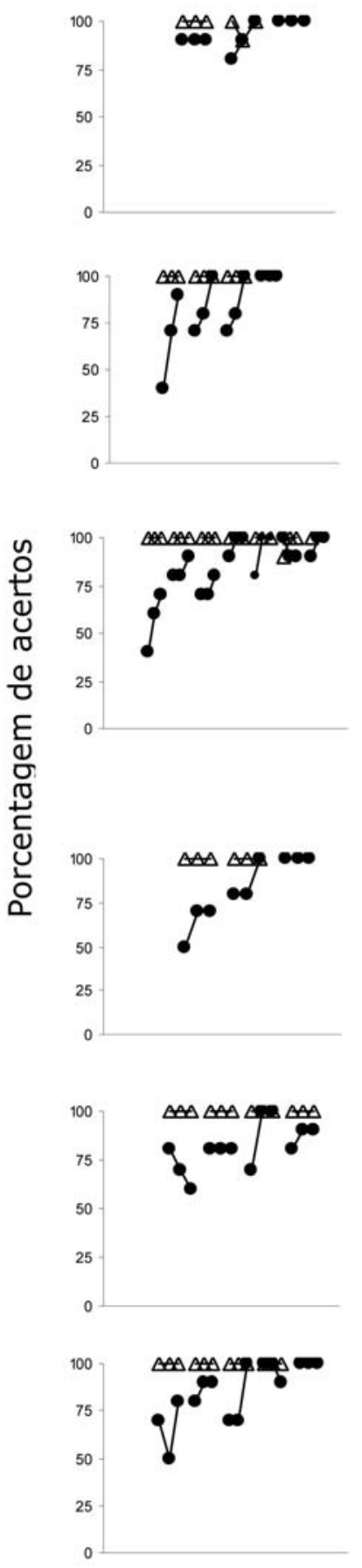

2
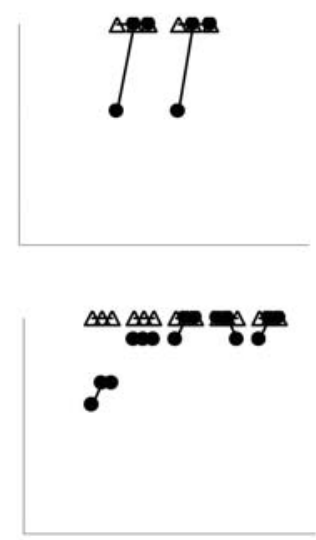

๑
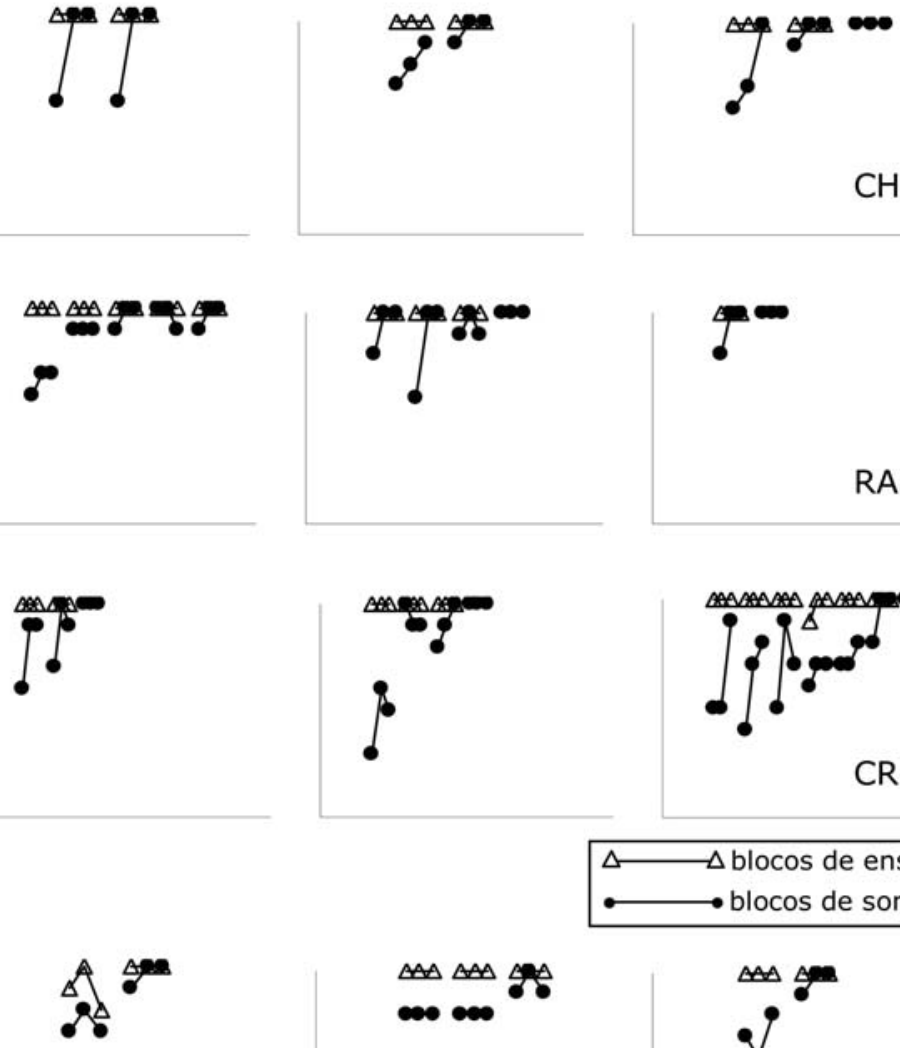

$\mathrm{CHL}$

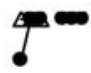

\section{RAS}
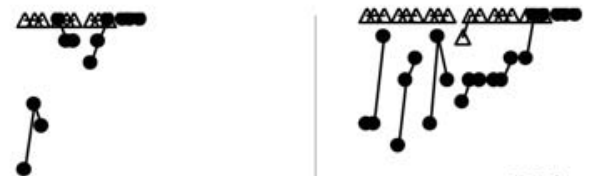

CRL blocos de sonda
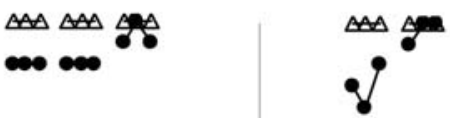

FA]
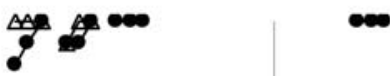

TEO
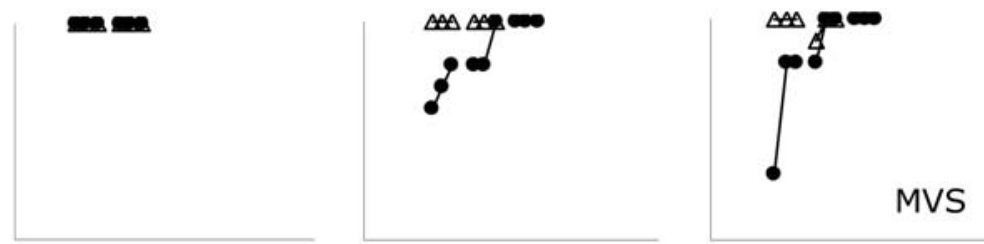

\section{Ciclos de ensino e sondas}

Figura 4. Porcentagem de acertos na leitura de palavras, em blocos sucessivos de tentativas de ensino (triângulos vazios) e de sondas (círculos cheios), para cada participante ao longo dos quatro conjuntos de palavras no Módulo 2. Cada ponto representa um bloco de 10 tentativas e cada conjunto de três blocos representa uma sessão. Os blocos de ensino e de sondas para um mesmo valor no eixo das abscissas pertencem a um mesmo ciclo. 
da palavra falada para a palavra impressa que era apresentada simultaneamente, mas o aluno poderia apresentar acertos desde a primeira tentativa, se apenas reproduzisse oralmente a palavra ditada, mesmo que não atentasse para a palavra impressa. No entanto, as sondas de leitura forçavam o participante a se confrontar com a palavra impressa e respostas incorretas nas sondas confirmariam o controle ecóico no bloco precedente, enquanto respostas corretas indicariam desenvolvimento do controle de estímulos pela palavra impressa (comportamento textual). Como pode ser observado, nos blocos de sonda de leitura as porcentagens de acertos eram inicialmente baixas e aumentaram gradualmente ao longo das sessões sucessivas, descrevendo uma curva típica de aprendizagem; as porcentagens de acertos baixas (especialmente para os três primeiros participantes) ou intermediárias nas sondas iniciais aumentaram gradualmente, até atingir 100\%, e todos os participantes atingiram o critério de aprendizagem em todos os quatro conjuntos de palavras ensinadas no Módulo 1 (Figura 3), assim como nos quatro do Módulo 2 (Figura 4). No segundo módulo, o desempenho dos participantes foi semelhante ao observado no primeiro, exceto por uma tendência a uma aquisição mais rápida (indicada seja pela menor quantidade de treino até o critério ou por maiores porcentagens de acertos desde as primeiras sondas).

Os dados dos participantes com repertório inicial mais pobre em leitura indicaram que eles tenderam a realizar mais vezes cada passo até atingir o critério de $100 \%$ em todos os blocos de ensino e de sonda, do que os alunos que tinham um repertório de entrada com maior porcentagem de acertos em leitura (ainda que esse repertório também fosse incipiente). Esse aspecto dos resultados também replica os encontrados por Gallo e de Souza (2004): o repertório de entrada dos alunos interage com o procedimento e alunos com alguma competência inicial em leitura se beneficiam mais rapidamente das condiçôes de ensino envolvidas no procedimento.

Com a exposição continuada ao procedimento, o número de repetições do procedimento com um mesmo conjunto de palavras tendeu a diminuir, como mostram especialmente as porcentagens de acertos dos participantes CHL e RAS. É notável que alunos com histórico de fracasso escolar tenham aprendido a ler conjuntos de 10 palavras com uma média de 18 exposições ao primeiro conjunto de palavras (isto é, 18 tentativas com cada palavra ensinada), média essa que foi reduzida para 15 , 12 e 12 exposiçóes para os demais conjuntos do Módulo 1. No Módulo 2 as médias foram 15,8 , 9 e 9, para os quatro conjuntos de palavras. Essa tendência à aprendizagem mais rápida, tanto em número de blocos de ensino, como nos níveis iniciais de acerto, sugere que a experiência sob as contingências de ensino pode ter resultado não só na aprendizagem do comportamento textual, mas também na aprendizagem de como aprender (como lidar com a tarefa, o que deveria ser feito) e o comportamento textual foi ficando cada vez mais proficiente à medida que eles continuavam sendo expostos ao programa de ensino. Esse padrão de desempenho sugere que, além de favorecer a aprendizagem discriminativa, as conseqüências para o desempenho, incluídas no procedimento, tinham valor reforçador, uma vez que mantiveram os alunos engajados, realizando as tarefas experimentais e aprendendo o que era ensinado. Esse não é um efeito trivial, considerando-se que os alunos tinham história de fracasso na escola e, de início, 
apresentavam freqüentes comportamentos de fuga e de esquiva de qualquer atividade que envolvesse material impresso.

É preciso considerar que o procedimento poderia favorecer que o comportamento do aluno ficasse sob controle apenas da palavra dita$\mathrm{da}$, dificultando o controle pelo texto; esse efeito de bloqueio (Catania, 1999; Kamin, 1969; Rescorla, 1967) pode ocorrer quando dois estímulos ocorrem simultaneamente, mas um deles já tem uma função sobre o comportamento (no presente estudo, a função discriminativa da palavra falada, controlando a imitação vocal do participante) e o estímulo novo, redundante com o primeiro, não adquire a mesma função. No entanto, efeitos de bloqueio não foram observados neste estudo nem no anterior (exceto, talvez, nos primeiros blocos de ensino). Conforme discutido por Gallo e de Souza (2004), mesmo que tais efeitos pudessem ter ocorrido nos blocos iniciais de ensino, a alternação entre tentativas de ensino e tentativas de sonda, nas quais a palavra ditada era omitida, pode ter estabelecido contingências que favoreceram a aprendizagem da relação palavra ditada - palavra impressa. Se o aluno aprendia essa relação, ele podia apresentar respostas corretas nas sondas e concluir as "liçôes" com um conjunto de palavras, prosseguindo então para um novo conjunto. No presente estudo, além de concluir o treino, o aluno ainda tinha a oportunidade de ler o livro de histórias. A sucessão dos dois tipos de ciclos no procedimento (um bloco de ensino sistematicamente seguido por um bloco de sondas) pode ter permitido que o aluno aprendesse o que era requerido em cada etapa e se comportasse em função dessas exigências.

Os resultados do delineamento de linha de base múltipla entre conjuntos de palavras, para avaliação dos efeitos do procedimento de ensino ao longo de sua aplicação, são apresentados na Figura 5. As porcentagens de acertos de cada participante estão apresentadas em coluna de painéis e sua identificação encontra-se no painel superior da respectiva coluna. As três primeiras colunas apresentam dados dos participantes com menor porcentagem de acertos no pré-teste e as três colunas da direita mostram os dados dos que leram algumas palavras no pré-teste. Os dados relativos ao Módulo 1 são apresentados na metade superior da figura e os relativos ao Módulo 2 são apresentados na metade inferior. A linha tracejada vertical separa a porcentagem de acertos na linha de base (à esquerda) e na retenção (à direita), após a aplicação do procedimento de ensino para cada conjunto de palavras. O quinto painel de cada módulo apresenta apenas dados de linha de base, uma vez que as palavras do quinto livro foram apenas testadas. Os triângulos representam a porcentagem de acertos de leitura das 10 palavras de cada conjunto nas cinco sondas sucessivas de leitura; cada teste, conduzido em duas sessões, avaliava 50 palavras, mas a análise de dados foi feita separadamente para cada subconjunto de 10 palavras. $\mathrm{O}$ círculo cheio, isolado, corresponde à leitura das 10 palavras do conjunto em contexto, isto é, durante a leitura da história (e permite verificar se os dados são ou não convergentes nas duas tarefas). $\mathrm{O} x$ indica que o dado foi perdido, seja por problemas técnicos na recuperação do arquivo de registro, seja por erro experimental; como as sessões de avaliação eram apresentadas em um arquivo separado, muitas das sessões previstas não foram conduzidas devido a que o experimentador seguia a seqüência do procedimento de ensino e quando se dava conta, tinha perdido a oportunidade de aplicar os testes (isto sugere a importância de se planejar também o 
Módulo 1

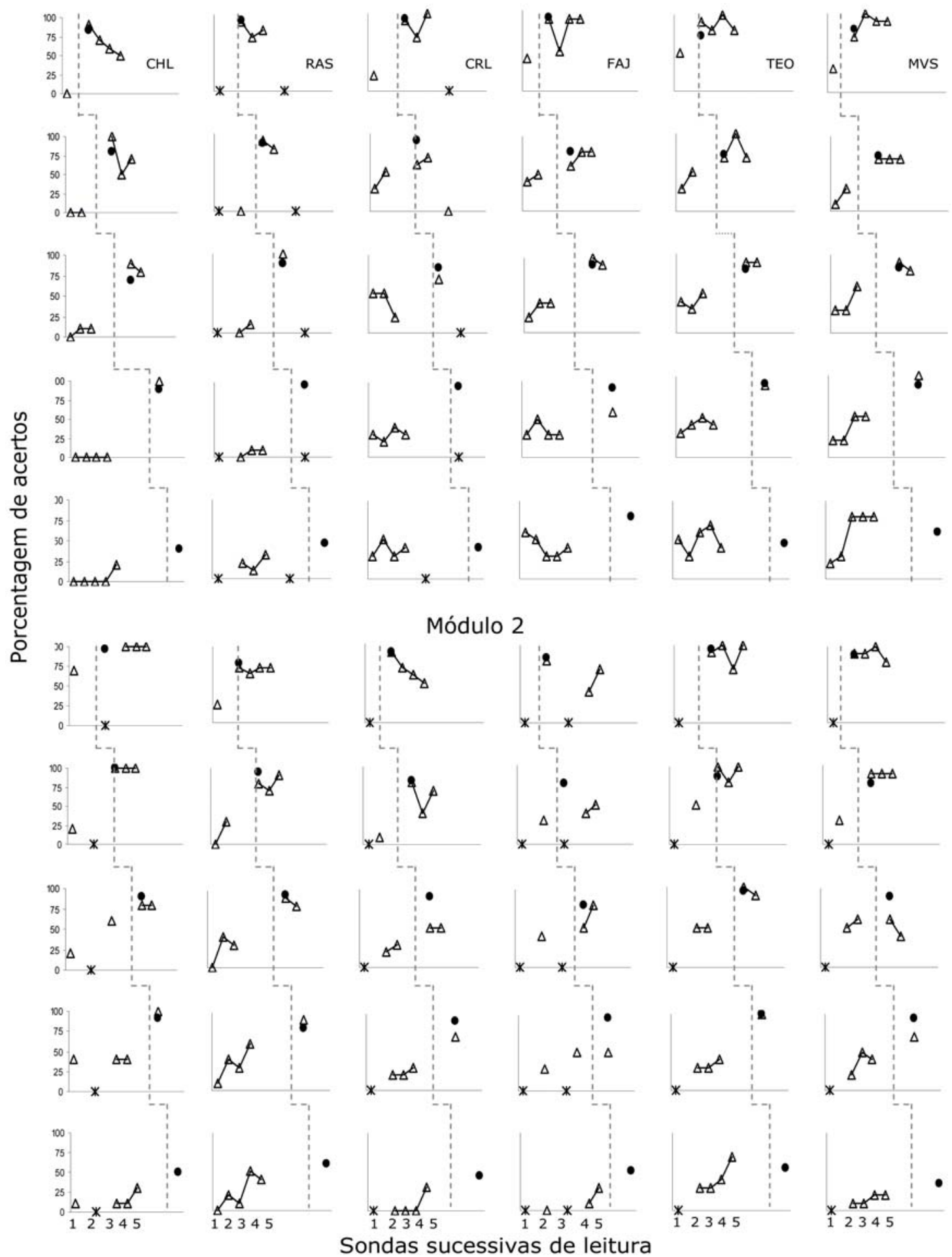

Figura 5. Porcentagem de acertos de leitura de palavras nas cinco sondas sucessivas de leitura nos Módulos 1 e 2 . A linha tracejada vertical separa as medidas de linha de base (triângulos à esquerda) das medidas de retenção, após o ensino das palavras (à direita). O círculo cheio indica a leitura das palavras inseridas no texto. $\mathrm{O}$ asterisco indica perda de dados. 
controle do comportamento do experimentador, especialmente quando há mais de um envolvido, como foi o caso do presente estudo, de modo a evitar erros desse tipo).

Os dados do Módulo 1 mostram que os três primeiros participantes apresentavam porcentagem de acertos baixa na leitura de palavras na linha de base, antes de serem ensinadas (o que replica e confirma os dados do pré-teste apresentados na Figura 2) e não mostraram tendência a aumentos nesse desempenho ao longo de avaliaçóes sucessivas com as palavras ainda não ensinadas, isto é, não generalizaram a leitura para palavras novas, como resultado do ensino de outras palavras nos passos precedentes. Após o ensino de cada conjunto, o desempenho dos alunos aumentou visivelmente, atingindo porcentagens geralmente acima de 70 por cento de acertos. Como os aumentos só ocorreram depois da aplicação do procedimento de ensino, isso evidencia que eles resultaram do procedimento e não de outras variáveis (como, por exemplo, o ensino em sala de aula). Portanto, o delineamento mostrou-se adequado para a demonstração do controle experimental (Sidman, 1960/1976; Tawney \& Gast, 1984; Almeida, 2003). Os dados nos testes após a fase de ensino podem ser tomados como medida de retenção (se o desempenho se manteve ou não, após o critério de aprendizagem). Em geral, ocorreu retenção, mas em níveis menores do que os $100 \%$ requeridos como critério na fase de ensino. Além disso, observou-se também uma ligeira tendência à perda de retenção no reconhecimento das palavras de um livro, à medida que as palavras dos outros conjuntos foram sendo ensinadas, especialmente para CHL, em relação aos Livros 1 e 2. Essa perda de retenção, aliada aos dados que mostraram que os alunos não generalizaram de um con- junto de palavras para outro, sugere que eles estavam reconhecendo as palavras como um todo e que não ocorreu o desenvolvimento de controle por unidades menores que a palavra. $\mathrm{Na}$ ausência de abstração das unidades menores (Alessi, 1987; Skinner, 1957), os alunos tinham que memorizar as palavras (as letras em seqüência em cada palavra), o que pode ter sido influenciado pelo número de palavras e pela competição com palavras novas. A falta de generalização, a despeito da alta porcentagem de reconhecimento das palavras ensinadas, também tem sido encontrada em outros estudos que empregaram palavras inteiras (de Rose, de Souza, Rossito, \& de Rose, 1989; de Rose, de Souza, \& Hanna, 1996; Hanna, Kohlsdorf, Quinteiro, Fava, de Souza, \& de Rose, 2008; Hübner-D'Oliveira \& Matos, 1993; Matos, Hübner, \& Peres, 1999), nem ensinaram explicitamente as correspondências som-texto (o código para as relaçôes arbitrárias entre esses dois tipos de estímulo). Esses estudos mostraram que empregando palavras inteiras, a generalização só passa a ocorrer à medida que o aluno é exposto a uma maior quantidade de treino e a uma maior variedade de palavras. Isso parece ter ocorrido nos dados de três participantes (CHL, RAS e CRL) no Módulo 2; os resultados nesse módulo replicaram, de modo geral, os do Módulo 1, exceto pelo fato de que foram observados episódios de aumentos na linha de base (antes do ensino), sugerindo o desenvolvimento, ainda que incipiente e variável, de generalização do comportamento textual. Além disso, os níveis de retenção tenderam a ser mais elevados e com menor tendência decrescente do que a observada no Módulo 1.

Os outros três participantes que leram algumas palavras no pré-teste também apresentaram acertos na fase de linha de base, isto é, já 
reconheciam pelo menos uma ou mais palavras selecionadas para serem ensinadas; um dos participantes (MVS) apresentou tendência crescente durante a linha de base (ver conjuntos 3 , 4 e 5), o que indica que este participante começou a apresentar comportamento textual generalizado após o ensino dos Conjuntos $1 \mathrm{e}$ 2 , reconhecendo as palavras dos conjuntos seguintes já no pré-teste, antes que fossem ensinadas. Depois do ensino, o desempenho dos alunos melhorou, os índices de acertos tenderam a ser maiores do que os dos três primeiros e a retenção, em geral, manteve-se elevada até o fim do procedimento (exceto para MVS, que apresentou ligeira tendência a queda na retenção das palavras do Conjunto 3, nos dois módulos). Quanto à leitura das palavras dos Livros 5 e 10, reservadas apenas para avaliação de generalização ao final de cada módulo, observa-se uma tendência a pequenos aumentos na porcentagem de acertos, para alguns dos participantes, ainda que em valores baixos e variáveis, o que sugere o desenvolvimento gradual de generalização do comportamento textual. Essa tendência também foi confirmada pela leitura das mesmas palavras, quando inseridas na história, como indicado pelo círculo cheio.

A variabilidade na generalização de comportamento textual quando são ensinadas palavras inteiras é um resultado com ampla generalidade experimental. Embora sua ocorrência ateste que as contingências de reforço para certas unidades de comportamento podem estender seus efeitos para unidades menores, inseridas nas unidades reforçadas (Skinner, 1957), o que tem significativa importância teórica, do ponto de vista de ensino é importante eliminar a variabilidade individual e ampliar os níveis de generalização. Estudos que manipularam dire- tamente o ensino de unidades menores que a palavra, juntamente com o ensino de palavras, mostraram que esse é um componente importante para o ensino de leitura que seja efetivo não apenas para ensinar um conjunto de palavras, mas para estabelecer as abstrações que possibilitam sua leitura, quando recombinadas em ampla variedade de novas palavras (Serejo, Hanna, de Souza \& de Rose, 2007; de Souza, de Rose, Cazati, \& Huziwara, 2003; Matos, Avanzi, \& Mcllvane, 2006). O procedimento empregado nesse estudo pode tornar-se mais efetivo para promover leitura generalizada se incorporar o ensino de unidades menores, acompanhando o ensino de palavras inteiras, de modo a favorecer o estabelecimento de relações entre grafemas e fonemas.

\section{Transferência da leitura de palavras na tela do monitor para a leitura em livros}

Os resultados de todos os participantes sugerem que, em geral, o controle de estímulos nos dois suportes (palavra isolada na tela versus palavra inserida no contexto da frase em uma página de livro) converge. A primeira medida encontra-se na Figura 5. O primeiro triângulo após a linha tracejada mostra a porcentagem de acertos na leitura das 10 palavras de cada conjunto, apresentadas na tela do monitor, no teste que se seguiu ao critério nos blocos de sonda daquele conjunto. O círculo cheio representa a porcentagem de acertos na leitura das mesmas 10 palavras quando apresentadas no livro correspondente. Em alguns casos, notase desempenho ligeiramente melhor na leitura no livro e, em outros, essa leitura foi menor que a leitura na tela. $\mathrm{Na}$ grande maioria das avaliações, contudo, as porcentagens de acertos foram bem próximas. Ambas as medidas foram sistematicamente maiores que as da linha de 
base (exceto para o 5o. livro, cujas palavras não foram ensinadas), confirmando o efeito positivo do procedimento de ensino sobre a leitura nas duas situações.

Uma segunda medida do comportamento textual na situação de leitura dos livros (para todas as palavras e não apenas para as ensinadas) é apresentada na Figura 6. A figura mostra, para cada participante individualmente, a distribuição percentual do desempenho de acordo com quatro categorias: acertos, respostas seguidas pela apresentação de modelos como correção ou como dica atrasada, e autocorreções. As barras cinzas se referem aos livros dos quais as palavras foram ensinadas (quatro no Módulo 1 e quatro no Módulo 2) e as barras brancas se referem aos livros reservados para avaliação de generalização (5 e 10). Todos os participantes apresentaram porcentagens elevadas de acertos na leitura dos livros contendo as palavras que foram ensinadas, variando de 66,3 a 95,9\%. As porcentagens de acertos também foram altas nos livros de generalização (barras brancas), embora tenham sido, em geral, ligeiramente menores que as porcentagens de acertos nos demais livros. A apresentação de modelo foi empregada com maior freqüência como correção para palavras lidas incorretamente (mais do que como dicas para palavras não lidas), especialmente para os alunos CHL e RAS. A freqüência de uso de dicas e a de auto-correções foi relativamente baixa para todos os participantes, em todos os livros. O emprego do modelo tendeu a decrescer e a leitura correta tendeu a aumentar, para a maioria dos participantes, à medida que os alunos prosseguiam de um livro para outro, dentro de cada módulo, de modo que a leitura do quarto livro foi, geralmente, melhor que a dos livros precedentes. A Figura 7 apresenta, para cada partici- pante individualmente, a porcentagem de acertos na leitura de todas as palavras do livro (barras brancas) e na leitura das palavras selecionadas inserida no contexto do livro (barras cinzas). As barras hachuradas indicam o desempenho em leitura dos livros de generalização (5 e 10). De modo geral, todos os alunos foram capazes de reconhecer, nos livros (em meio a várias outras palavras), as palavras que haviam aprendido a reconhecer isoladamente na tela do computador, além de serem capazes de ler outras palavras que não aquelas diretamente ensinadas. Em geral, a porcentagem de acertos foi maior para as palavras ensinadas, aproximando-se de $100 \%$ para vários dos participantes, principalmente nos livros finais de cada módulo.

Para os livros de generalização, a porcentagem de acertos na leitura apresentou-se mais baixa que os demais, com porcentagens de acertos na faixa dos 20 a $50 \%$ de acertos.

A ocorrência de controle textual pelas palavras apresentadas no livro (suporte e contexto diferentes da situação de ensino) evidencia a importância de se incluir, nas situações de ensino, oportunidades para uso funcional do comportamento aprendido em ambientes naturais nos quais se espera que o comportamento ensinado ocorra (Stokes \& Baer, 1977). Por outro lado, o reconhecimento de palavras não diretamente ensinadas, por parte de alunos que claramente não apresentavam comportamento textual no início do estudo, especialmente nos primeiros livros, sugere que, na ausência do controle por unidades textuais mínimas, a situação provavelmente envolvia outras fontes de controle de estímulos; algumas possibilidades incluem as ilustrações no texto e, também, o contexto da história. Por exemplo, em uma frase como "o sapo pulou na lagoa", se o aluno havia aprendido a ler sapo e lagoa e conhecia a história 


\section{Modelos}

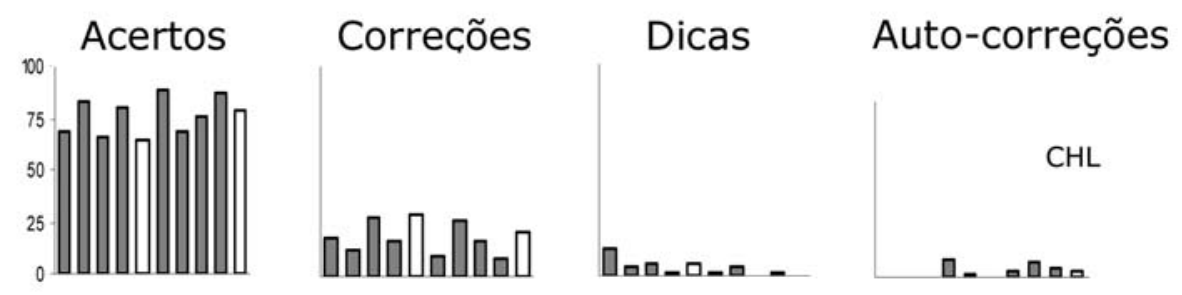

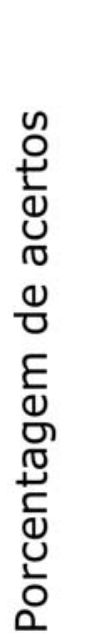
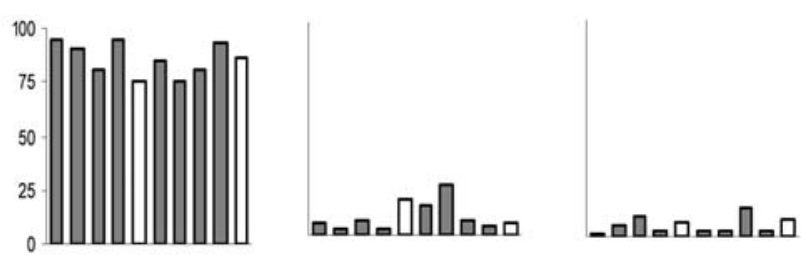

RAS
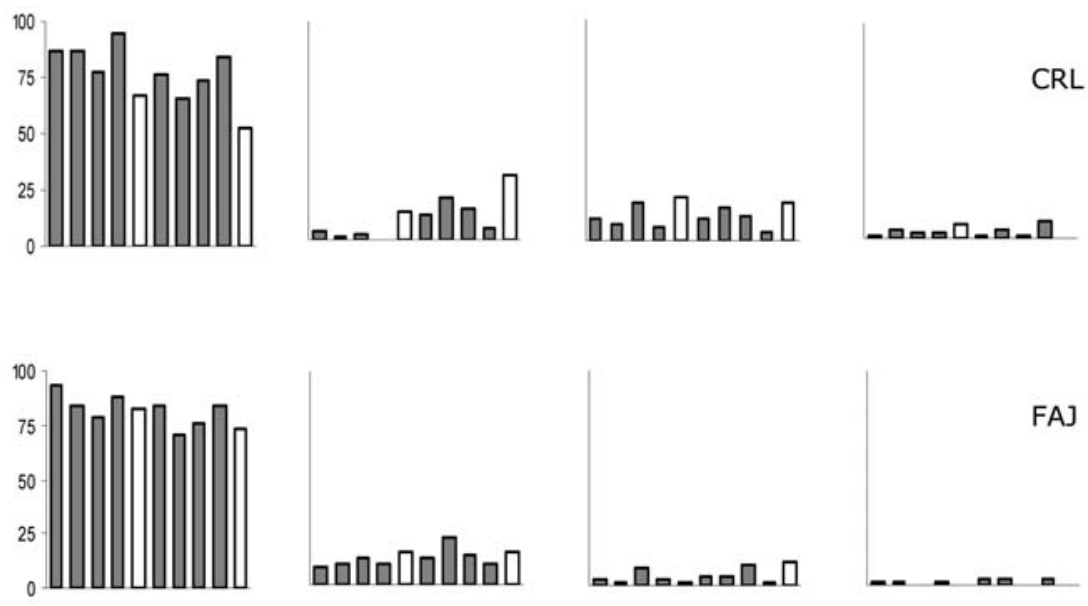

FA]
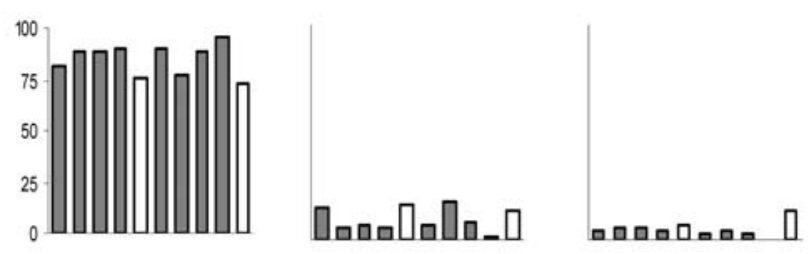

TEO
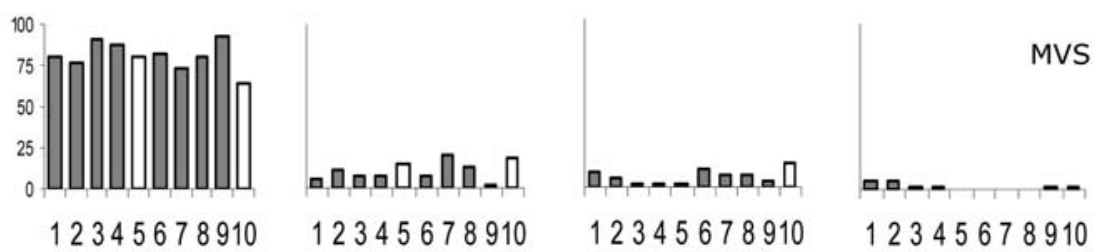

\section{Livros}

Figura 6. Porcentagem de acertos, de modelo-correção e de modelo-dica atrasada (providos pelo experimentador) e de autocorreções na leitura em livros para participantes individuais, ao longo dos dois módulos. As barras cinzas correspondem aos livros com palavras ensinadas ( 1 a 4 e 6 a 9) e as barras brancas correspondem aos livros empregados para avaliação de generalização de leitura (5 e 10). 

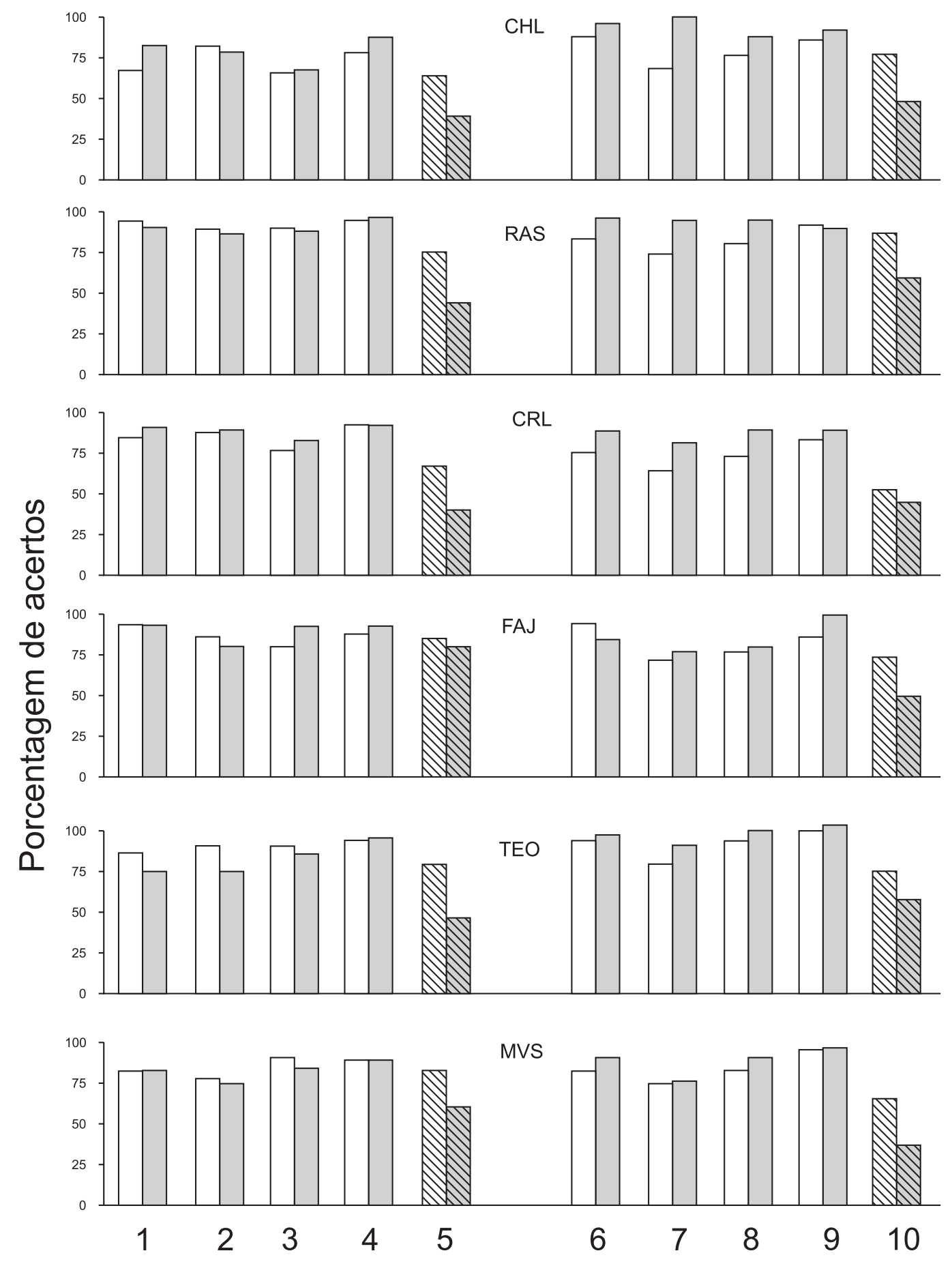

Livros

Figura 7. Porcentagem de acertos na leitura de palavras inseridas nos livros. As barras brancas representam a porcentagem total (todas as palavras do livro) e as barras cinzas representam a porcentagem de leitura das palavras ensinadas. As barras hachuradas indicam o desempenho em leitura dos livros de generalização (5 e 10). 
por tê-la ouvido antes, seria possível que ele também falasse $o$ sapo (e não meramente sapo) e na lagoa (e não apenas lagoa). Além disso, o conhecimento prévio da história podia permitir que, mesmo que não fosse capaz de ler pulou, o aluno pudesse prever ou antecipar que esta era a palavra naquela frase (de Rose, 2005; Clay, 1968, 1993). Pode-se argumentar que esses comportamentos não constituem leitura (o domínio do código alfabético, que precisa ser explicitamente ensinado), mas uma importante corrente da literatura sugere que são extremamente importantes para favorecer a compreensão de leitura. Não basta ser capaz de apresentar comportamento textual se o indivíduo não compreende o que lê, se não pode reagir à sua própria fala como ouvinte (de Rose, 2005; Skinner, 1957). Assim, as tentativas apresentadas pelos alunos sugerem que o procedimento pode ser útil em uma etapa inicial de ensino de leitura e, principalmente, no desenvolvimento do "gosto" ou "interesse" pela leitura. Observações anedóticas durante a leitura nos livros permitiram identificar incidências nas quais os alunos "descobriam" a palavra, não pela decodificação, mas pelo contexto (novamente, embora isso seja "adivinhação" e não leitura, esse tipo de "descoberta" pode ter tido um efeito importante sobre a motivação dos alunos - cf. Santos \& de Rose, 1999; 2000, e por isso tem seu papel nessa fase inicial, embora claramente seja necessário avançar para o domínio do código, quando então o aluno será capaz de decodificar qualquer palavra). Nos episódios de "descoberta" o aluno, surpreso, ao notar que leu corretamente, muitas vezes olhava novamente para a palavra e até a repetia, antes de prosseguir com a leitura. Foi observado, também, que o aluno continuava acertando a palavra em suas ocorrências subseqüentes no texto e até em novos textos e isso ficava especialmente nítido no caso de preposiçôes e conjunções, que não eram diretamente ensinadas. Esses resultados estão de acordo com a sugestão de que, após ter adquirido comportamento textual diante de algumas palavras, ouvir o próprio comportamento pode funcionar como reforço diferencial, permitindo que as respostas corretas (modeladas pela comunidade verbal) sejam fortalecidas e que as incorretas possam ser autocorrigidas (de Rose, 1999).

\section{Considerações finais}

Iniciando pelo comportamento ecóico (ou imitação vocal), o procedimento permitiu que o aluno tivesse muitas oportunidades de enunciar as palavras e de ouvir seu próprio comportamento. A transferência do controle de estímulos da palavra falada pelo computador para o texto impresso na tela como estímulo discriminativo para a palavra falada pelo aluno pode ter sido favorecido pela alternação sistemática das tentativas de ensino (que apresentavam simultaneamente a palavra e a palavra impressa) com as tentativas de sonda (apresentação da palavra impressa). Os resultados indicaram que todos os alunos adquiriram o comportamento textual sob controle das palavras impressas ensinadas, sugerindo que o procedimento foi eficaz para ensinar o reconhecimento de palavras e para manter o comportamento do aluno na realização das tarefas experimentais. Os seis participantes concluíram o procedimento e a quantidade de exposição aos blocos de ensino apresentou tendência decrescente com o decorrer do estudo, sugerindo um efeito cumulativo das aprendizagens prévias. A retenção de leitura em avaliações periódicas após a aprendizagem de cada conjunto de palavras permaneceu relativamente alta, exceto para alu- 
nos com repertório de entrada mais baixo, que apresentaram perdas na retenção para os conjuntos de palavras ensinados inicialmente, mas passaram a reter a maioria das palavras dos conjuntos ensinados nas fases finais do programa de ensino. Esse resultado sugere que aqueles alunos estavam reconhecendo a palavra como um todo, mas não eram capazes de efetivamente fazer a correspondência ponto a ponto som-texto que caracteriza o comportamento textual.

Todos os participantes também reconheceram uma parcela considerável das palavras novas, tanto quando o reconhecimento foi medido na leitura de palavras novas (enquanto mantidas em linha de base) no computador, como na leitura de histórias, que continham palavras não ensinadas. Os resultados obtidos na avaliação do repertório de leitura realizada antes e depois da aplicação do programa de ensino também demonstraram a ocorrência de reconhecimento generalizado de palavras impressas. A generalização é essencial na formação de um leitor competente e independente. Seria praticamente impossível aprender a ler diretamente todas as palavras de uma língua; nos sistemas de escrita alfabética, como o português, o domínio de correspondências somtexto das unidades alfabéticas básicas permite que o aluno abstraia e leia essas unidades nas múltiplas combinações nas quais elas podem ser encontradas em diferentes palavras (de Rose, 2005; Mueller, Olmi, \& Saunders, 2000; Skinner, 1957). As abstrações relevantes podem se desenvolver por meio de diferentes procedimentos e processos; embora o presente procedimento não tenha lidado diretamente com o ensino de unidades menores que palavras, o ensino de 80 palavras, garantindo variação e repetição de unidades como sílabas e letras (cf. Hanna et al., 2008; Hübner-D’Oliveira \&
Matos, 1993), e a oportunidade de leitura de textos cujo conteúdo o aluno conhecia (e que possivelmente eram interessantes para ele), possibilitou o desenvolvimento de abstraçóes que foram suficientes para garantir os níveis de generalização observados. No entanto, esses níveis ainda ficaram muito aquém do esperado para uma leitura competente, o que sugere que o procedimento pode se tornar mais eficiente se incorporar o ensino explícito de controle por unidades textuais menores que a palavras (sílabas e unidades intra-silábicas) ou mesmo se ensinar diretamente as correspondências somtexto no nível de fonemas e grafemas (o código arbitrário que deve ser dominado para uma leitura generalizada competente).

O programa de ensino aliou um procedimento que favoreceu o estabelecimento do comportamento textual (discriminação entre diferentes palavras impressas, com controle discriminativo por cada palavra impressa; cf. Skinner, 1957) à possibilidade de reforçamento natural. Para tanto, ensinou palavras que faziam parte de histórias que os alunos conheciam na modalidade oral e que passaram a ler, quando tinham um repertório de reconhecimento de palavras que permitia assegurar alta probabilidade de acerto já na primeira oportunidade de contato com a história impressa. Quando ele encontrava dificuldades na leitura da história, a intervenção do adulto consistia apenas em apresentar o modelo de resposta correta, permitindo que a leitura fluísse em ambiente tranqüilo, acolhedor e com a menor quantidade possível de controle aversivo (que poderia ocorrer, por exemplo, se tivessem sido empregadas correçôes, explicaçôes ou instruções extensas, comentários depreciativos, insistência para tentar decifrar palavras, etc.).

Os resultados ainda mostraram que os alu- 
nos que já apresentavam um repertório inicial de leitura tenderam a repetir menos os blocos de treino e de sondas, principalmente a partir do Módulo 2, e que apresentaram generalização mais cedo do que os alunos que não liam antes do programa de ensino. Isso sugere que o procedimento pode ser especialmente útil para fortalecer e acelerar a leitura de alunos que apresentam comportamento textual em graus ainda incipientes.

\section{REFERÊNCIAS}

Almeida, M.A. (2003). Metodologia de delineamento de pesquisa experimental intra-sujeitos: relatos de alguns estudos conduzidos no Brasil. Em M.C. Marquezine, M.A. Almeida, \& S. Omote. (Orgs). Colóquios sobre pesquisa em educação especial, (pp. 63100). Londrina: Eduel.

Alessi, G. (1987). Generative strategies and teaching generalization. The Analysis of Verbal Behavior, 5, 15-27.

Catania, A.C. (1999). Aprendizagem: comportamento, linguagem e cognição (Trad. Deisy G. de Souza et al.). Porto Alegre: Artes Médicas Sul.

Clay, M. (1968). Reading errors and self-correction behaviour. British Journal of Educational Psychology, 39, 47-68.

Clay, M. (1993). Reading recovery: A guidebook for teaches in training. Portsmouth, NH: Heinemann.

da Silva, A.C., Sparano, M.E., Cerri, M.S.A., \& Carbonari, R. (1997). A leitura do texto didático e didatizado. Em L. Chiappini (Org.), Aprender e ensinar com textos didáticos e paradidáticos (pp. 3193). São Paulo: Editora Cortez.

de Rose, J.C. (1999). Explorando a relação entre ensino eficaz e manutenção da disciplina. Em F.P. Nunes Sobrinho, \& C.B. Cunha (Orgs.). Dos problemas disciplinares aos distúrbios de conduta: Prática e Reflexões (pp. 1-24). Rio de Janeiro: Qualitymark Editora. de Rose, J.C. (2005). Análise comportamental da aprendizagem de leitura e escrita. Revista Brasileira de Análise do Comportamento, 1, 29-50.

de Rose, J.C., de Souza, D.G., Rossito, A.L., \& de Rose, T.M.S. (1989). Aquisição de leitura após história de fracasso escolar: equivalência de estímulos e generalização. Psicologia: Teoria e Pesquisa, 5, 325-346.

de Rose, J.C.C., de Souza, D.G., \& Hanna, E.S. (1996).

Teaching reading and spelling: Exclusion and stimulus equivalence. Journal of Applied Behavior Analysis, 29, 451-469.

de Rose, T.M.S. (1995). Compreensão de leitura: ensino e conhecimento. Tese de Doutorado, Instituto de Psicologia, Universidade de São Paulo, São Paulo, SP. de Souza, D.G., de Rose, J.C., Cazati, T., \& Huziwara, E.M. (2003). Generalização recombinativa na aquisição de leitura. Apresentado na XXXIII Reunião Anual de Psicologia da Sociedade Brasileira de Psicologia. Resumos de Comunicaçôes Cientificas, p. 34. Duran, A.P. (1981). Padrão da comunicação oral e compreensão da comunicação escrita na universidade: Estudo no nordeste. Tese de Doutorado. Instituto de Psicologia, Universidade de São Paulo, São Paulo.

Ferster, C.B. (1967). Arbitrary and natural reinforcement. Psychological Record, 22, 1-16.

Gallo, A.E., \& de Souza, D.G. (2004). Ensino de reconhecimento de palavras com base em procedimentos de aprendizagem sem erro. In: E.G. Mendes, M.A. Almeida, \& L.C.A. Williams (Orgs). Temas em Educação Especial: Avanços recentes (pp. 271-282). São Carlos: EdUFSCar.

Goldstein, H. (1983). Training generative repertoires within agent-action-object miniature linguistic systems with children. Journal of Speech and Hearing Research, 26, 76-89.

Hanna, E.S., Kohlsdorf, M., Quinteiro, R.S., Fava, V.M.D., de Souza, D.G., \& de Rose, J.C. (2008). Diferenças individuais na aquisição de leitura com um sistema lingüístico em miniatura. Psicologia: $T e-$ oria e Pesquisa, 24, 45-58. 
Horcones. (1992). Natural reinforcement: A way to improve education. Journal of Applied Behavior Analysis, 25, 71-75.

Hübner-D’Oliveira, M.M. \& Matos, M.A. (1993). Controle discriminativo na aquisição da leitura: efeito da repetição e variação na posição das sílabas e letras. Temas em Psicologia, 2, 99-108.

Harzem, P., Lee, I., \& Miles, T.R. (1976). Effects of pictures on learning to read. British Journal of Educational Psychology, 46, 318-322.

Kamin, L.J. (1969). Predictability, surprise, attention and conditioning. Em E.B.A. Campbell, \& R.M. Church (Orgs.). Punishment and aversive behavior (pp. 279296). New York: Appleton-Century-Crofts.

Matos, M.A., Avanzi, A.L., \& McIlvane, W.J. (2006). Rudimentary reading repertoires via stimulus equivalence and recombination of minimal verbal units. The Analysis of Verbal Behavior, 22, 3-19.

Matos, M.A., Hübner, M.M.C., \& Peres, W. (1999). Leitura generalizada: procedimentos e resultados. Em: R. A. Banaco (Org.). Sobre Comportamento e Cognição: Aspectos teóricos, metodológicos e de formação em análise do comportamento e terapia cognitivista, Vol. 1, (pp. 470-488). Santo André, SP: ARBytes. Miura, R.K.K. (1992). Oportunidade de resposta seguida por modelo: um procedimento para o desenvolvimento de leitura em alunos com dificuldades de aprendizagem. Dissertação de Mestrado, Programa de Pósgraduação em Educação Especial, Universidade Federal de São Carlos, São Carlos, SP.

Mueller, M.M., Olmi, D.J., \& Saunders, K.J. (2000). Recombinative generalization of within-syllable units in prereading children. Journal of Applied Behavior Analysis, 33, 512-531.

Rescorla, R.A. (1967). Pavlovian conditioning and its proper control procedures. Psychological Review, 74, 71-80.

Rosa Filho, A., de Rose, J.C., de Souza, D.G., Hanna, E.S., \& Fonseca, M.L. (1998)._Aprendendo a ler e a escrever em pequenos passos. Software (Versão 1.0).

Santos, J.A., \& de Rose, J.C. (1999). A importância do reforço natural na formação do hábito de leitura. Revista Olhar, 1, 37-42.

Santos, J.A., \& de Rose, J.C. (2000). Interesse de crianças por leitura: Um procedimento para identificar o valor reforçador relativo da atividade. Acta Comportamentalia, 8, 197-214.

Serejo, P., Hanna, E.S., de Souza, D.G., \& de Rose, J.C. (2007). Leitura e repertório recombinativo: efeito da quantidade de treino e da composição dos estímulos. Revista Brasileira de Análise do Comportamento, 3, 191-215.

Sidman, M. (1960/1976). Tactics of scientific research. Boston: Authors cooperative.

Skinner, B.F. (1957). Verbal behavior. Englewood Cliffs, New Jersey: Prentice Hall.

Snow, C.E., Griffin, P., \& Burns, M.S. (2005). Knowledge to support the teaching of reading. São Francisco: John Wiley \& Sons.

Stokes, T.F., \& Baer, D.M. (1977). An implicit technology of generalization. Journal of Applied Behavior Analysis, 10, 349-367.

Tawney, J.W., \& Gast, D.L. (1984). Single subject research in special education. London: Bill \& Towell Company.

Witter, G.P. (1997). Psicologia: Leitura e Universidade. Campinas, SP: Editora Alínea.

Submetido em 1 de novembro de 2007 Aceito em 14 de dezembro de 2008 